Rev. Chil. Pediatr. 68 (5); 223-229, 1997

\title{
Meningitis tuberculosa
}

\author{
Juan E. Gonzálcz G. '; Ana Chávez P. 2. Ernesto Payá G. ${ }^{3}$; Julia Chadid S. ${ }^{2}$
}

\begin{abstract}
Resumen
Lo huberc losis merincea zor:stifuye la lo no nás grave de esta irfección, con fecuentes secuelas y cla letalidac Se describe un actane de 13 meses, sin vacuna $3 C Q$, quien rientras era some-ido o irivestigarión por una áez án

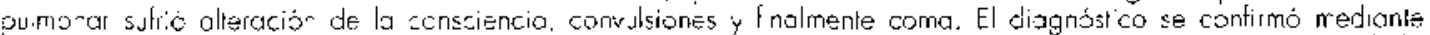
cul:ivo de barı c de Koch en ccrien co jostriç 90 das después. En niñss merores de cinco ar̃os a incuoacićn de la tuberc, losis puede ser thy ccrlc. puciendcse desarrolla: merirgitis en menos de res meses cesce la exposición al agerite cousol. En Chile la tuberulosis meningeo es oucc frezuente, sin erborgo, hay que tenelo presente, ya que su

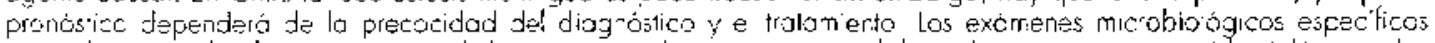
lienen ba sens bi ijoc, por c cue el diagnóślico se taso en gran redida on los cntececentes epidemiológ cos, las

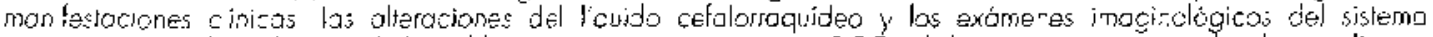
neviost. ia amplio cotertura de la pobtac ón con inmunizazion ccn BCG, el diognosticc frecoz. sobre bases clintcas y epcem clícicas. y el tratemiento oportuno y agresivo son la clave para ieducir la lealidac y as secuelas de esta grcue entermecad en rirics menores.
\end{abstract}

[Palabros clave: reningilis, luberajlosis reninges.]

\section{Meningeal tuberculosis}

Meningeat tuberculosis s one the the mast serious farms of the disease. The case cl a BCG unvaccinated I3 months old infont who plesented with seizures, uncorsciousriess and comma while he was bee shucied becouse ot pumonary symploms. Diagrosis was utmately contirned oy isolation of Mycobocteritum tuberculcsis from gastric con'erit zultures 90 days later. In children less han 5 yea:s old. incubatior period of meningeol tubercu csis may be as shast as three months. In Chile whe BCG vacc nalion is roulinely performed to newborn infarts this torm of the disease is ather intequent but physicians should re olew to this posibility beccive proçnosis deperids criticaily on tinely diagnosis and reotment. Jue to low sensibility of specitic microbiologicol tests. initial diagnosis mis be based on epidemiologyco, climica. cereorospinol fud culccherrica anolysis and neuromages findings.

|Key words: ruperculosis, menirgeal.|

La cuberculosis continúa siendo de alta prevalencia en el mundo, $y$ su incidencia ha vuelto a aumentar en los últimos años en muchos países $^{t-3}$. En Estados Unidos entre 1985 y 1993 aumentó 13\% en la población general y $40 \%$ en los menores de 14 años. Las formas severas de

1. Línidal de Neurología, Servicio de Pediatría Hospital Exiequiel Gonzáley Cortes

2. Unidad de Intecciosos, Servicio de Pediatria Hospital Exequiel González Cortés.

3. Laboratorio de Mitrobiología, Hospital Exequicl Gonzúlez Cortés: la enfermedad, incluyendo la meningitis, se registran con mayor frecuencia en los niños menores de 5 años, lo que podría guardar relación con inıadurez de la respuesta inmune. En Chile, la incidencia de tuberculosis ha disminuido sostenidamente desde tasas de mortalidad de 200,4 por 100000 habitantes en 1948 hasta 2,8 por 100000 habitantes en 1994. Sin embargo, la enfermedad sigue siendo un importante problema de salud y será necesario extremar los esfuerzos para evitar que recrudezca, como ha ocurrido en norteanérica y algunos países elropeos $^{4-9}$. La meningitis es la forma más grave 
de la tuberculosis en laclantes y niños pequeños. $y$ es letal fatal si nu sc incicia oportunamente el tratamiento adecuddo $1.3 .5 .6 .10 \%$.

Con al proposisto de reforzar el estado de alejtit para el diagnóstico de csta enfermedad se describe el siguiente caso y y se revisan brevemente los aspectos más relevantes de ella.

\section{Caso Clínico}

Varén. Gestación y parto nurmales. Nació en Australia. A) nacer peso ? 5.30 g. su lalla cra $50 \mathrm{~cm}$. No recibio Yacuna BCG. Crecio bien y mosiro buen desarrollo

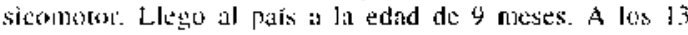
meses sufriti una enfermedad agloda saracterizada por lebriculas, Ios y coriza gue cedieron con tracamiento sittmontice Lor súntomas se repitierun en tres oportunidades. pior lo que se de hizo uni jadiogratíta de tórax, la que loos11 unat imagen de condensación del lobulo superior del puluon detceho quc fic inlempretada cormo neumonia y tra-

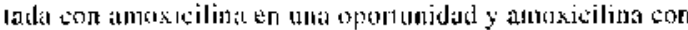
ácido ciatulínico en orra, dismmayclido los sinnomas sin yue se mondilicase la imagen radiolígica. Cuarenta y ocho horas después de suspender el segundo tratumiento con antitiúlicos. se reinició la fiebre, por io que ingresós al hospilaj. Estaba en buenas condiciones generales, afebril, eutrofico (peso $10 \mathrm{~kg}$. (alla $79 \mathrm{~cm}$ ). con escasos estertores pulmonarus hútnedos. Sin cicarnz BCG. En la radiografia de tórax (figura I) se registraba una imagen densa en el lóbulo superior del puluín derecho y ensanchamiento del mediastino. Hematoctito $31 \%, 20200$ leucocitos $x \mathrm{mmr}^{3}$. neutsufilo $81 \%$, velocidat de sedimentación de los eritrocitos (VHS) 38 $\mathrm{m} / \mathrm{m} / \mathrm{h}$. proteina ( reactiva $24 \mathrm{mg} / 1$ Tíno normal. signos de atelectosia retráctil y neumopalía crónica del lóbulo supcrior derecho en la tonnografía axial computatizada (TAC) de lirax. Seis dias después de ingresar, su temperatura subio a $39,5^{\circ} \mathrm{C}$, y dos días después se agrovo bruscamente con deterioro rápidamente progresivo de su eslado de concichcia y tres episodios de convulsiones bicves, caracterizados por fasciculaciones faciales y movjmicntus de succión. El líquido celialorraquidea (LCR) era de aspecto claro y trasporente, albuimina $82 \mathrm{mg} / \mathrm{dl}$. glucosa

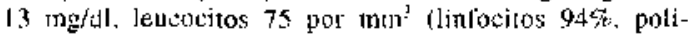
morfonuclea'ss 6\% de resulados negativos, glicemia $97 \mathrm{mg} / \mathrm{dl}$. El deteriors de 1a concientia zumentú hasta llegar al coma en las 12 h siguicules cuando se registraban puntajes de Glasgow 7 a 8 . pupilas hiporteastivas. desviación de la rijicada hasia la derecha. paresia facial perilërica derecha y hemiparesia
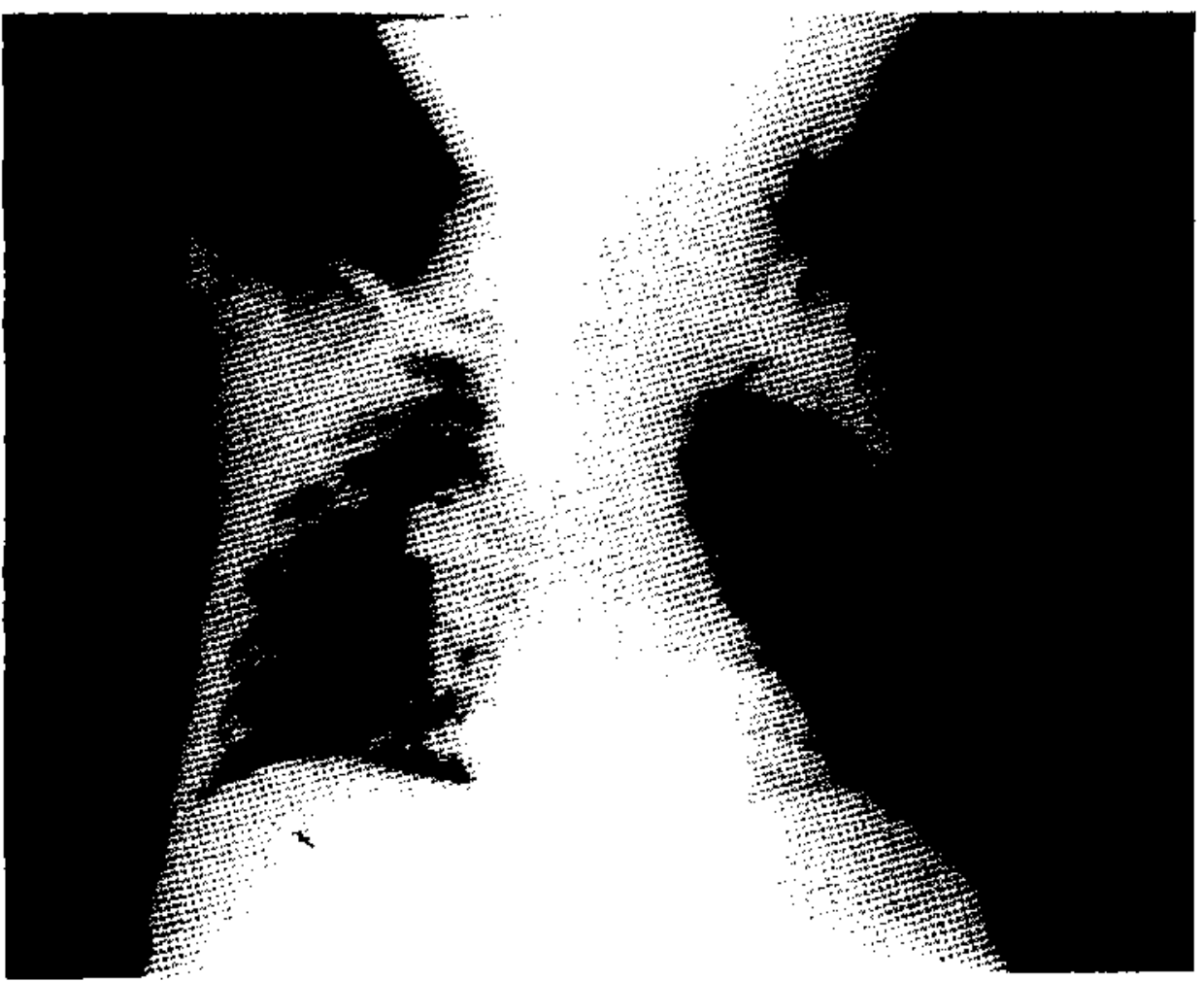

Figura 1: Radjoglatía de törax: muestra condensación dal lobulo superior del pulmón derecho y ensanchalunitulo del mediastino. 
brayuiocrural derecha, requiriendo ventilación mecánica. En Ia TAC cerebral habia siguos de edema cerebral. dilatación de los tres ventriculos y una lesión de baja densidad cn el terricorio de arteria perforante izquierda con aspecto de infarto serebral. Se indicó tratamiento con eslreptomicina, isoniazida, rifampicina, pırazinamida y corticoesteroides. En el LCR de dos das después la concentración de albúmina era $99 \mathrm{mg} / \mathrm{Jl}$, la de glucosa $6 \mathrm{mg}$ dd, con 158 leucocitos por $\mathrm{mm}^{3}$ y $93 \%$ de linfociros Desde to cuarto din de tratamicnto su consciencia mejoró progresivanuence (Glasgow 12-13). persistiendo hemiparesia deretha $y$ paresia facial derecha central. En la TAC ceretoral (figura 2) al $5^{6}$ dín se régistraba disminución de los signos de hipertension endocraneana. moderada dilatación triventricular, signos de iufarto de los núcleos caudado y cśpsula interua izquierda $y$, en controles posteriores. bidrocefalia esiable, sin hipertensión endocraneana y una zona hipodensa de infarto que no varió. La linciún de Ziehl-Nielsen del líquido cerebroespinal, la búsqueda de infección por Crintecocctrs, VIH y el estudio inmunologíco del paciente, asi como ia pesquisa de TBC en la familia, dieron resulados negativos. Al completar 31 dias de tratamiento con drogas antituberculosis y curlicondes, egresó para continuar con trataniento ambulatorio. Como el diagnóstico no había sido confinnado, al tercer mes de evolución se realizs resonancia nuclear inagnética (figuras 3 y 4), con angiografía de resonancia cercbral, en la que se registró imágents de extensa meningitis granulomatosa y lesiones isquémicas de arterins lenticuloestriadis izquierJas. infartos conticales en el cerricorio de la arteria cercbral media e hidrocetaliz compensada. Los culives de Kuch

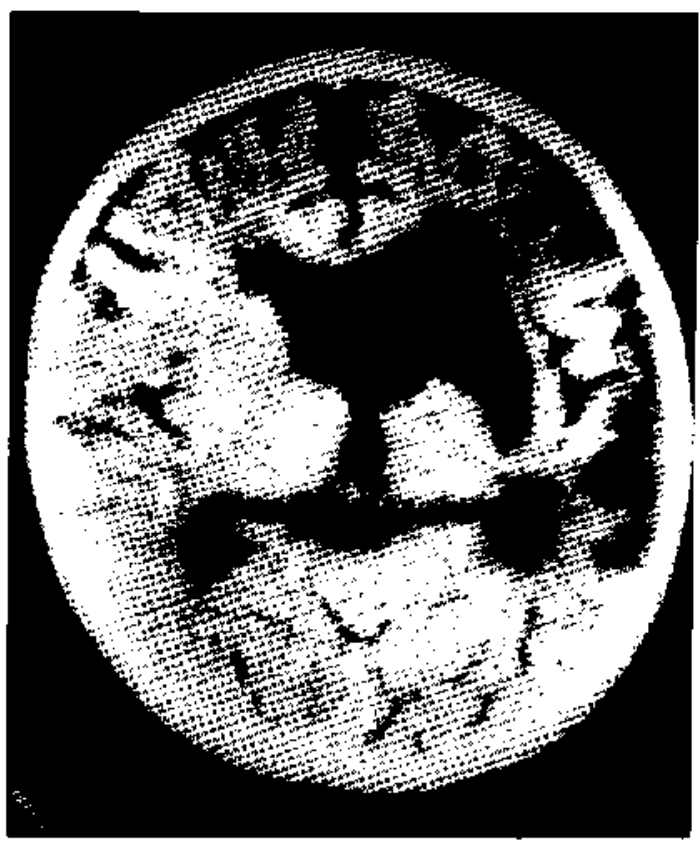

Figura 2: Tomoglafia axial computadorizadi del cerebro: hidrocetalia friventricular y lesión de baja densidad en la región del nucleo caudado y cápsula interna izquierda. del líquido cefalomaquídeo fueron negativos a los 30 y 60 días, pero dos cultivos de contenido gástrico dieron resullados positivos a los 90 días para Mycobacteritm luber'dtosris. con 2 y 4 colonias respectivasnente. Después de doce meses de tratamiento, y rehabilitación, a los 14 meses de evolución sólo quedaba leve hemiparesia facial braquial y crural derecha, de predominio distal bracuial, siendo el desarrollo siconotor y habílidades lingüísticas normales para la edad.

\section{Comentario}

La tuberculosis del sistema nervioso central es parte de la enfermedad diseminada cn el lactante o una reactivación de la enfermedad en adolescentes y adultos. Cuando ocurre la diseminación linfohematógena en la infección primaria tuberculosa, los bacilos se distribuyen en todo el organismo, incluyendo médula ósea, hî-

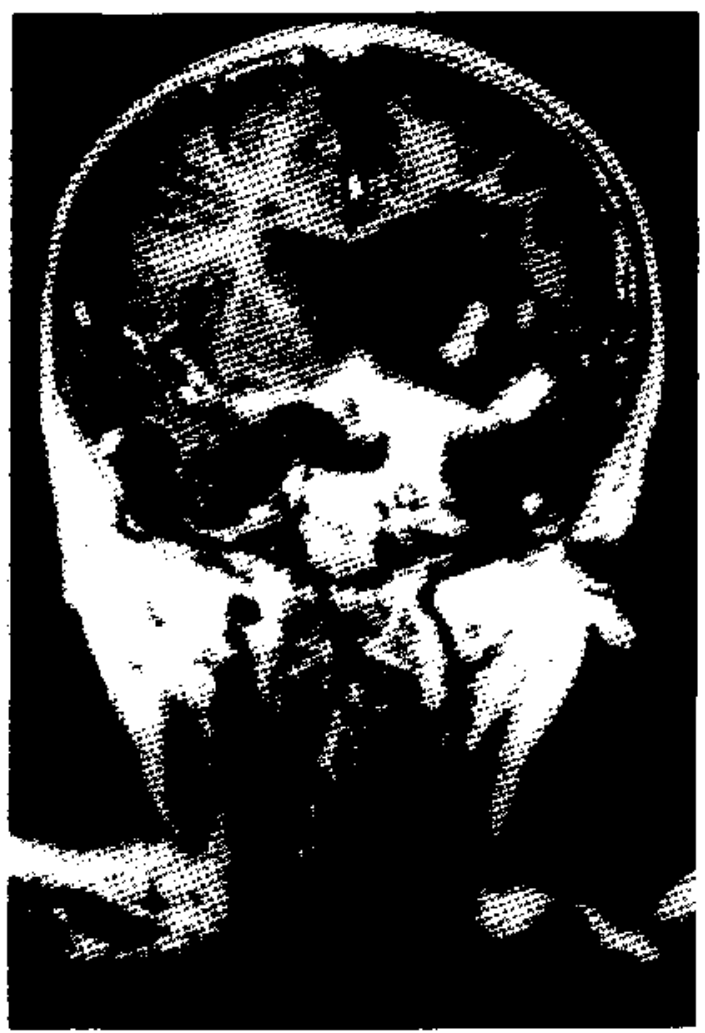

Figura 3: Resonancia nuclear magnética serebral, jmagen coronal en T! con gadolinio: engrosumiento meningeo basal. lesiones isquśnicas en la región caudotalamica iz. quierda y corticales de ramas de arteria cerebral media izquierda e hidrocefatia. 


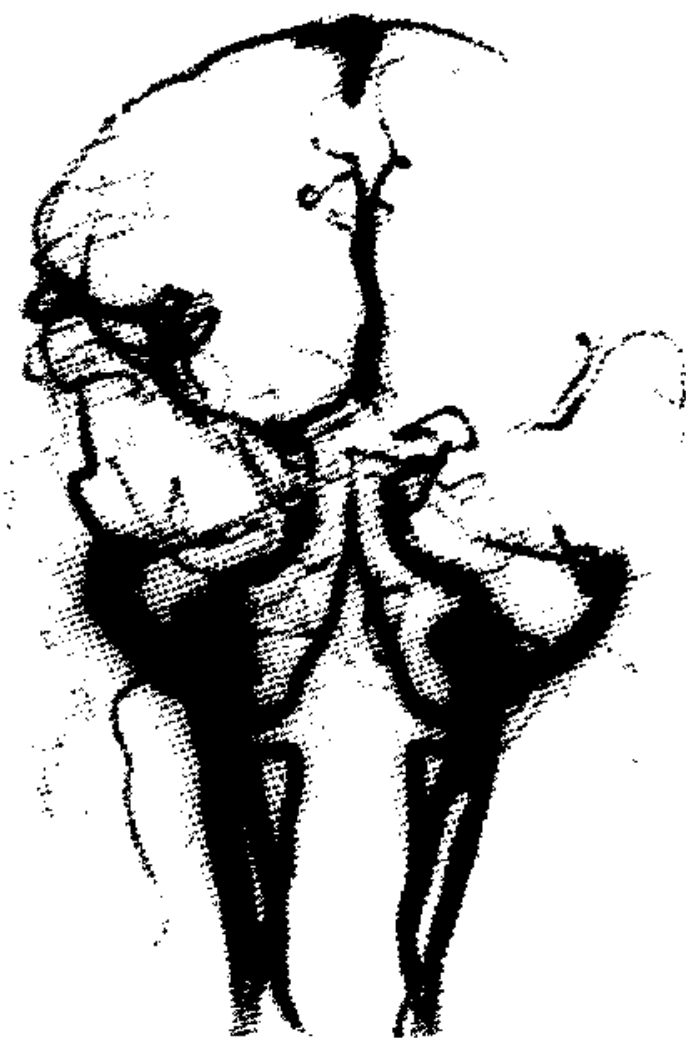

Figura A: Angiografía poi resonancia nuclear magnéticu cerebral: la arterid cerebral media izquierda tiene menor grosol y unenor ramíricación que la contralateral normal.

gado, bazo, plexos coroideos, cráneo, meninges y mídula espinal. donde se forman los tubérculos caseosos. Los bacilos son inicialmente contenidos en los tubérculos, pero $5 \%$ de los huéspedes expuestos, especialmente los niños pequeños, son incapaces de mantener una respuesta inmune adecuada, desarrollando una tuberculosis diseminada. En cl niño mayor los tubérculos pueden haberse instalado previamente y mantenerse estables por años $y$, en relación a una alteración de la inmunidad celular, como ocurre en pacientes con linfoma o SIDA, los bacilos contenidos en su interior se multiplican reactivando la entermedad, 3,6.11. Al romperse un tubérculo al espacio subaracnoideo, se inicia la inflamación, como consecuencia de una rcacción de hipersensibilidad inducida por los microorganismos y asociada al matcrial antigénico existente dentro del cerebro y el espacio subaracnoideo. Independicntemente de dónde el tubérculo descargue, la reacción inflamatoria es siempre más marcada en la base del cerebro. Tres características dominantes de la lesión explican las manifestaciones clínicas de la meningitis tuberculosa: la aracnoiditis proliterativa, la vasculitis con trombosis e infarto y la hidrocefalia. La aracnoiditis profilerativa es más marcada en la base del cerebro, en las cisternas basales y en la región de la cisura de Silvio. Puede ser gruesa, gelatinosa, como una masa que se extiende desde el puente hasta los nervios ópticos, mấs prominente en el átea del quiasma óptico. A medida que progresa el proceso inflamatorio va adquiriendo el aspecto de una masa fibrosa que envuelve los pares craneanos y afecta su función. La vasculitis se caracteriza por el compromiso de los vasos de la base del cerebro o de la arteria cerebral media como consecuencia de la extensión de la aracnoiditis basilar o por la directa invasion de la adventicia por la micobacteria. Esto lleva a la trombosis e infartos multifocales cerebrales, especialmente en los núcleos basales, corteza cerebral, puentc y cerebelo. La hidrocefalia comunicante, la mas frecuente, es secundaria al compromiso inflamatorio de las cisternas basales que puede impedir la circulación de líquido cefalurraquídeo y su reabsorción. Menos frecuente es la obstrucción del acueducto de Silvio, con la consiguiente hidrocelalia obstructiva $\mathbf{a}^{10-1 .}$ ?

Las manifestaciones clínicas de la tuberculosis meníngea son de comienzo gradual, sólo ocasionalmente abrupto, caracterizado por fjebre, y suele ser marcado por una convulsion. En la presentación clínica se distinguen tres etapas: la prodrómica se caracteriza por la fiebre proJongada, signos inespecíficos como irritabilidad, cefalca intermitente, anorexia, náuseas, vómitos y letargo progresivo. Al cabo de 2 a 3 semanas se expresa la etapa meningítica con signos de hipertensión endocraneana, signos meníngeos, parálisis de nervios craneales (especialmente III, IV y VII pares) y alteración inicial de consciencia (somnolencia a confusión). Posteriormente la enfermedad puede progresar rápidamente llegando al sopor o coma. presencia de convulsiones y hemiplejia, hemiparesia 0 paraplejia que caracterizan la tercera etapa o paralítica ${ }^{1,3-6.8 .10,11}$. Las formas cljnicas atípicas incluyen la presentación como meningitis aguda; convulsiones y compromiso de pares cranea- 
nos precoces; hidrocefalia. con cefalea, diplopia. edema de papila y trastornos visuales precediendo los signos meníngeos, y forma encefalítica con estupor o coma y convulsiones sin signos de meningitis. En estos casos el LCR revela pleocitosis love y proteína normales o levemente elevadas ${ }^{\text {I. }} 14$.

El diagnóstico de meningitis TBC se confirma mediante aislamiento del bacilo de Koch en el LCR. sin embargo este procedimiento es de bajo rendimiento. El cultivo de LCR tiene una positividad de $50 \%$ y la baciloscopía 10 a $40 \%$. para este último examen la muestra de contenido gístrico ha demostrado mayor sensibilidad que el lavado broncoalveolar ${ }^{4}, 5,8,10,15$. Otras pruebas diagnósticas incluyen la determinación de adenosin deaminasa (ADA) en el LCR, enzima producida por linfocitos $T$ diferenciados, determinación que ha sido especialmente útil en el diagnóstico de TBC pleural. Se ha establecido la scnsibilidad del método en $89 \%$ y la especificidad en $91 \%$, con un punto de corte de 7,l unidades por litro; pueden existir falsos positivos, especialmente en meningitis virales y más raramente en meningitis bacteriana y en tumores del sistema nervioso central $(S N C)^{4.5 .16-18}$.

Otras aproximaciones diagnósticas incluyen la detcrminación de anticuerpos antiPPD y antiBCG en LCR y la determinación de ADN del agente en LCR, ya sea por téenica de hibridización isonda genética) o por amplificación génica ( $P C R$ ). En Chile se ha establecido una sensibilidad de 90\% y especificidad de $89 \%$ para la técnica de determinación de anticuerpos antiPPD (IgG, IgM) y antiBCG (IgG) mediante enzimo inmunoensayo. La especificidad de la amplificación por reacción en cadena de polimerasa del ADN del M. tuberculoso es cercana al $100 \%$, pero con una sensibilidad no mayor del $50 \%$. Con nuevos cambios en la técnica hoy se tienen resultados de alta sensibilidad en el diagnóstico de tuberculosis pulmonar, para to cual se dispone de reactivos comerciales (Genprobe(B) y Roche(6)) con sensibilidades de 98 a $100 \%$ y especificidades de 87 a $90 \%$, pero no hay experiencia en su aplicacion para el diagnóstico de tuberculosis meníngea ${ }^{19-22}$.

Debido al bajo rendimiento de los exámenes microbiológicos, el diagnóstico de meningitis tuberculosa se apoya en otros exámenes de laboratorio y en los antecedentes epidemiologi- cos. Las alteraciones del líquido cefalorraquídeo san de la mayor utilidad para el diagnóstico, siendo lo más característico glucosa baja (20 a $25 \%$ de la glicemia), aumento de la concentración de proteínas (entre 100-300 mg\%) y pleocitosis linfocítica (entre 100-500 por $\left.\mathrm{mm}^{3}\right)^{1}, 3,5,8,11.74$. En alrededor de la mitad de los niños afectados se encuentran alteraciones en la radiografía de tórax, que incluye signos de complejo primario, compromiso miliar, lesiones del parénquima, ganglios mediastínicos o derrame pleural ${ }^{1,5}$. La reacción del PPD es de poca utilidad pará el diagnóstico, siendo positivo (mayor de $10 \mathrm{~mm}$ en el período agudo de la meningitis en menos del $50 \%$ de los casos ${ }^{2}, 8$.

Puesto que el principal sitio de transmisión de la infección a un niño es su hogar, cuando se sospeche este diagnóstico debe investigarse a toda la familia por antecedentes de tuberculosis. los que se encuentran en $40 \%$ de los casos y hacer pesquisa de enfermedad activa, lo que suelc ocurrir en $70 \%$ de ellos $1-4,6, x, 10$. La incubación de la luberculosis meníngea o la enfermedad diseminada en menores de cinco años puede ser muy corla (6 a 8 semanas) ${ }^{2,6}$. Los criterios microbiológicos y clínicos para defīnir un caso como TBC del sistema nervioso cerebral incluyen uno de los primeros o dos o más de Ios segundos ${ }^{6}$ (tabla).

La tomografía axial computadorizada (TAC) y la resonancia nuelear magnética (RNM) han contribuido a ampliar los conceptos sobre la patogénesis de la énfermedad y facilitado la valoración clínica, reemplazando con ventajas a la neumoencefalogfafía $y$ la angiografía $11,12,14$. En la TAC cerebral, según la etapa clínica de la meningitis tuberculosa, las imágenes pueden ser normales o de aracnoiditis basilar, hidrocefalia o infarto secundario a vasculitis. En bajo porcentaje se detecta un tuberculoma calcificado. Un hallazgo importante y característico es la hidrocefalia triventricular o cuadriventricular, según la localización de la obstrucción ${ }^{1,4}$, 5, 10-12.14. La aracnoiditis basilar se puede manifestar por crecimiento inespecífico de las cisternas basales, que aumenta con el medio de contraste ${ }^{14}$. Los infartos se ven como áreas de baja densidad en los núcleos basales o en las regiones perisilvianas de la superficie cerebral 11. 14.23.24. En la resonancia nuclear magnética se observan las mismas anormalidades pero con mayor precisión y sensibili- 


\section{Tabla}

Criterien de lubereulosis del sistema nervioso central

Criterjos nuicrobiológiems: uno de Jos siguientes:

*: Aislamentis de M.tutrefettosis en el liquido cefatoraquideo.

* Signos y síntomas neurológitos anormales, alteraciones del líguido celaboraquideon romografía axjal o resonancii nuclear tompatibles con tuherculosis del sistema merviosos y aislaniento de M.suberctorsis de cutulquier sitio

Criterias clínicos: signos o síntomas ueurológicos anormales a más de dos de los siguíentes:

$\Rightarrow$ Contactir con adulto con iuterculosis tontagiosal

* PP[1 > 10 mon a $>5$ untu si el nijo luvo contacko esrecho con aduito infectadij.

: Altracions's de likpido cefalorraguder sia oth causa infecciosid

* Alteraciones de la lomografía axial o 1esonancia nuclear de] craneo conpatihles eon tuberculosis del sistema nuriuso central.

dad. Se ven mejor el crecimiento meníngeo tasal y cl del cpéndimo ventricular con medio de contraste. Fs también más sensible para delimilar zonas isquémicas y pesquisar tuberculomas en localizaciones especiales como hipotálamo, siendo especialmente útiles para observal lesiones de tronco cerebral unédula ${ }^{14.25}$.

El tratamiento de la meningitis TBC debe inicjarse apenas sc sospeche csta en base a criterios clínicos y epidemiologicos. sin esperar su confirnación, ya que el atraso determina mayores secuclas y tetalidad ${ }^{3}, 10,26$. Si bien hoy no hay cstricto acuerdo sobre los medicamentos que clegir ni la duración del tratamiento, está establecido que se deben utilizat al menos dos agentes bactericidas a los cuales el agente inficelante sea susccptible ${ }^{2,5,6.10,27}$. Para decidir el esquema se debe considerar la crcciente resislencia de $M$. tuberulesis a las drogas, que puede ser primaria (el paciente es infectado por un organismo ya resistente a una o más de cllas) o sccundaria (cuando emergen organismos resistentes durante el tratamiento) ${ }^{1.22} 27$. La Academia Estadounidense de Pediatría recomienda emplear isoniazida, rifampicina, pirazinamida y estreptomicina diariamente los primeros dos meses. Luego, durante diez meses, isonazida, rifampicina y pirazinamida diariamente o dos veces por semana ${ }^{1.6,8,36}$. Se proponc asociar corticoesteroides a los medicamentos antituberculosos aludidos, pues pucden disminuir significativamente la letalidad $y$ la frecuencia y magnitud de las secuelas neurológicas 1,3,13,26. Sin embargo. su uso rutinatio no está definitivamenle establecido, rescrvándose para los casos en que ocurre deterioro clínico después de administrar el tratamiento específico o cuando hay signos de hipertensión intracrancana (ctapas Il a 1il). Si se emplean, se recomienda hacerio por 4 a 6 semanas y disminuir gradualmente la dosis en 2 a 3 semanas, usando predrisona ( 1 a $2 \mathrm{mg}$ • $\mathrm{kg} \cdot \mathrm{d})$, dexametasona $(0.5$ a $1.5 \mathrm{mg} \cdot \mathrm{kg} \cdot \mathrm{d}) \mathrm{o}$ metilprednisolona $(0,5$ a $0.8 \mathrm{mg} \cdot \mathrm{kg} \cdot$ d) por via intravenosal 1 . 8.26

Oro aspecto del tratarniento es el quirúrgico, pues algunos sugieren la instalación preco\% de derivaciones para el lícuido cerebroespinal en las elapas I y I] con signos de hidrocefalia en la tomografía. Sin embargo, cs común en todos los casos alguna dilatación en los ventriculos y se considera que esta, por sí misma, no es indicación para el procedimiento, sino el deterioro expresado por el empcoramiento de síntomas y signos neurológicos asociados a la hidrocelalia. En cambio en los niños en ctapa III es posible que el drenaje ventricular externo inicial permita controlar mejor la presión intracraneanat 3.5.

A pesar de los excelentes agentes quimioterápicos, las secuelas neurologicas de la meningitis TBC son frecucntes $y$ la letalidad siguc siendo entre 15 y $60 \%$, siendo indispensable para controlarlas la actuación precor $1,3,4,6,8,10$. Por esta razón, a pesar de su baja frecuencia cn Chile, es necesario tener presente esta infección del SNC y, dado que los exámenes microbiológicos específicos muestran poca sensibilidad para el diagnóstico, este se debe basar en antecedentes epidemiológicos, cuadro clínico, alteraciones del LCR y estudio ncurorradiológico. Sin embargo, en algunos casos estos criterios pueden no estar presentes, lo que pone de manifiesto la necesidad de disponer de una prueba confiable y rápida de confirmación.

En niños, especialmente menores de 5 años, el período de incubación de la TBC puede ser muy corlo, pudiendo desarrollarse meningitis $y$ enfermedad diseminada en menos de tres meses desde la exposicion, lo que destaca la importan- 
cia de la vigilancia epidemiológica y manejo de contactos $^{2} 6$. Entre las medidas de control jucya un papel iniportante la vacunación $\mathrm{BCG}$, que en Chile alcanza coberturas muy elevadas, superiores a $95 \%$ de los recién nacidos y $90 \%$ de los escolares de primer año básico y puede ser un factor importante en la baja prevalencia de la enfermedad. pues, a pesar del debate sobre su eficacia, numerosas publicaciones muestran que reduce el riesgo de infección TBC en alrededor de $50 \%$, con mayor protección contra las formas más severas como meningitis y enfermedad diseminada ${ }^{4,5,7}$. El aumento de la frecuencia de desplazamientos entre páses exige la revisión del calcndarto de vacunación de los inmigrantes.

\section{Referencias}

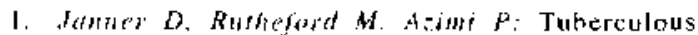
nteningitis in children. Pediatric Emergency Cate (9) 3; 9: 281-284

2. Sifike $J$, Corres A: Mandgement of mycobacterial infection and disease in children Pediarr Intect Dis J 1095: $14: 455-470$.

3. Smith M. Starke I. Margiris IR: Tuberculosis and oponunistic mycobacteral infections. Ju: Fejgen RI). Chersy JD. Eds. Texibook of pedialric infecticus discoses. Third edition, WS Saunders Counpany, Philadelphia J952: I.32I-J.36I.

4. Cusless $R G$. Miklow $C D$ : Contral nervous system tuberculous in childrew. Pediatr Neurol 1991; 7: 720. 724.

5. Nevifon RW: Tuberculous meningitis. Archives of disease in childhood. 1994: 70: 364-366.

6 Dew CA, Sturke J. Che I.T: Clinical and public health. Aspects of tuberculous meningitis in childres. J Pediate 1995: 127: 27-33.

7. Coldit GA. Brewer F. Berker CS, et al Efficacy of $B C G$ vaceine in the prevention of tubcroulosis. JAMA 1994: $271: 698-70$ ?

B. Mance MY. Nolve FS. Nobmias AJ. Jarus WR: Use of polymerasa chain reaction for diagnosis of tuberculous meningitis. Pediala Infect Dis J 1994; 13 : I 54-156.

9. Relerencia MINSAL (en prensa).

10. Wacker NJ. Comnos JD: Central nervous system 10. hereulosis in children: A review 30 cases. Pediatr Infect Dis J 1990; $9:$ : 359-549.
11. Lefmad $M$. Despres: Tuterculosis of the contral necrous system. In: Aminof MJ. Ed. Neurology and general mediciac. Sccond edition, Churchil] Livingstone luc.. New York 1995: 703-716.

12. Adtms $R$, Vitor $M$ : Principles of neurology. 5ih ed. Vew York: McGraw-Hill lnc, 1993: 616-618.

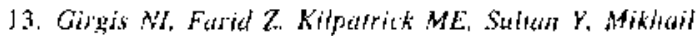
IA: Dexamethasone adjuntive treatment for tuberculous Inconingitis. Pediale Infect Dis J 1991; 10: I79-183.

14. Venna $N$. Sebin $T$ : Tuberculosis of nervaus system. 113: Feldman E. Ed. Current diagnosis in neurology. Mosby Year Book inc.. St. Louis Missouri 1994: 117 124

15. Kennedy $D H$. Fattom R.f: Tuberculous meningitis, JAMA 1979: $241: 264-268$.

16. Pirck MA. Gakis $C$ : Cerebrospinal fluid adenusine deamiase aclivity in tuberculous meningitis 1973; 14: $311-317$.

17. Rodrigur' E, Solo F. Velisuluez $C$ : Adenosin deaminesa cono test diagnostico de tuberculosis pleural. Enferm Resp Cir Torak 1987: 3: 182-187.

18. Detriel $T$ : New approaches 10 the rapid diagnosis of tuberculous meningitis. J Infect Dis 1987: 155: 599 602 .

19. Vatenzuela MT. Getciat P: Actudización en métodos diagnósticos de la meningitis mberculosa. Boletín ISP 1988: 27: 53-54.

20. Nowrdhock $G$. Areml $K$. Gunterd $B$, et at: Sensivity and specificity of PCR for detection of $M$. tuberculosis: $A$ bfind comparisson study among seven laboratories. J Clin Wicrobiol 1994: 32: 277-284.

21. Kirshnes $P$. Roxena J. Springer B. el at: Diagnosis of nycobaclerial infection by nucleic acid atnplification: 18 month prospective study. I Clin Microbiol 1996: 34: 304-312.

22. Pfiffer $G$, Kiscling $P$, Jahn $E$, ef at: Diagnosis petformance of annplified mycobacterium tuberculosis ditect test with cerebrospinal lluid, other nun respiratory and resparatory specimens. J Clin Microbiol 1996; 34: 8.74-841.

23. Astopoulos f. Chomelis Z. Christopoulos $S$, ef af: Sequencial computed thomography in tuberculous nicringitis in infanls and children. Comput Radiol 1984:8: 271

24. Piice HI, Danziger A: Computed lomography in cranial luberculosis. AJR 1978: 130:769.

25. Sitherman J. Hen'et $R$, Dobald P: MR of childhood luberculous meningitis. Neuroradjology 198R: 30 473.475.

26. American Actdemic of Pediatrite. Chemolherapy for tuberculosis in infants and thildren. Pediatrics 1992: $89 ; 161-165$ 